\title{
Astrometry mission wins German approval
}

Alison Abbott, Munich

The German Space Agency DLR last week selected DIVA (German Interferometry for Multichannel Photometry and Astrometry), an astrometry mission, as Germany's next small space science mission.

DIVA had been given top ranking by the DLR's ad hoc committee for space research. As a result, it now seems unlikely that there will be a second chance for ABRIXAS, the small German X-ray satellite that was lost last year, two days after launch, when its batteries failed (see Nature 399, 93; 1999).

A proposal for a new mission, ABRIXAS II, was ranked third behind MEGA (Medium-Energy Gamma Ray Astronomy), a gamma-ray astronomy mission.

DIVA will bridge what would have been a 20-year gap in astrometry missions between the switching off of the European Space Agency's mission Hipparcos in 1993 and the agency's sixth cornerstone mission GAIA, scheduled for launch in 2012 (see Nature 407, 277; 2000).

DIVA will measure the positions and motions of about 35 million stars in the Milky Way with high precision, and stars in other galaxies with lower precision. It will view 300 times more objects than Hipparcos, with a fivefold greater precision. GAIA will eventually measure 30 times as many objects as DIVA, with 20 times DIVA's precision.

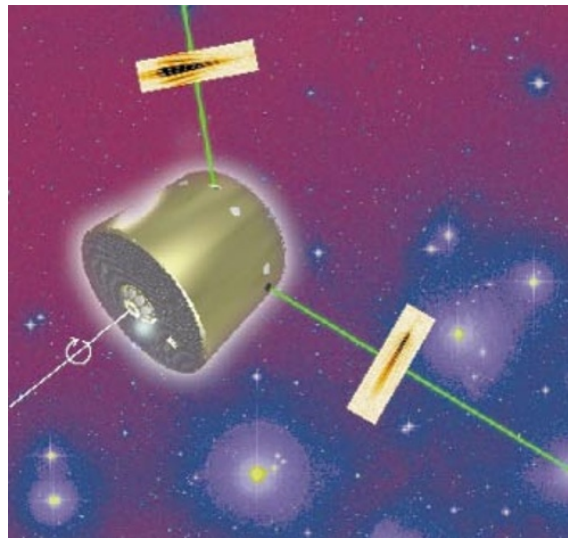

Map maker: DIVA will plot the positions and movements of millions of stars.

High-precision astrometry missions are important because a precise estimate of the mass of the visible Milky Way and the motions of its stars will help to characterize the amount and nature of the dark matter that astronomers suspect make up ninetenths of its mass.

DIVA will give European scientists the chance to carry the Hipparcos baton until GAIA arrives on the scene, says Siegfried Röser, DIVA's principal investigator and a senior scientist at the Astronomisches Rechen Institute in Heidelberg. "There is still enough Hipparcos expertise to train the next generation of astrometers on DIVA, so they will be able to pick up the scientific reins of GAIA."

Extra money will have to be found: DIVA will cost DM100 million (US\$45 million), twice the amount set aside by DLR for its next small mission. Röser is optimistic that three German states with interests in aerospace Baden-Wüttemberg, Thuringen and Bremen — will come up with the balance.

DIVA has also been helped by the Klaus Tschira Foundation, set up by one of the founders of the Heidelberg-based software company SAP. The foundation has donated DM1 million to DIVA's data analysis and sponsored an opera to raise money and promote private donations.

A further DM80,000 has been raised in this way. This is "very important for us because it demonstrates public interest in supporting science directly", says Röser.

Günther Hasinger, incoming director of the Max Planck Institute for Extraterrestrial Physics in Garching and a joint principal investigator of ABRIXAS II, says that DIVA's selection was fair. "It's hard to swallow," he admits, "but the community felt that X-ray astronomers were well served by ESA's XMM and NASA's Chandra."

He adds that ABRIXAS scientists are seeking alternative international partners to help finance the DM50 million project.

\section{Ig Nobel glory for levitating frogs and collapsing toilets}

\section{Steve Nadis, Boston}

Intelligence - and the lack of it - was the theme of this year's Ig Nobel prize ceremony, which celebrated its tenth anniversary at Harvard University last week.

Once a year, scientists gather to poke fun at themselves and others, hopefully without hurting too many feelings or careers. This time, ten prizes were awarded to winners from eight countries.

American researchers David Dunning and Justin Kreuger took the psychology prize for their 1999 paper, "Unskilled and unaware of it: how difficulties in recognizing one's own incompetence lead to inflated self-assessments".

Canadian biologist Richard Wassersug won the biology prize for his study, "On the palatability of some dry-season tadpoles from Costa Rica". On claiming the award, Wassersug explained that the tadpoles were "neither dry nor seasoned".

The physics prize went to Andre Geim of the Netherlands and Sir Michael Berry of England for using magnets to levitate both a frog and sumo wrestler. Magnets also featured in the medicine prize, awarded to Willibrord Weijmar Schultz, Pek van Andel and Eduard Mooyaart of the Netherlands for their MRI scans of male and female genitals in the act of coupling.

Scottish researchers Jonathan Wyatt, Gordon McNaughton and William Tullet captured the public health prize for their alarming report, "The collapse of toilets in Glasgow". Wyatt told the audience that the research had been dismissed for years "as a flash in the pan".

Three genuine Nobel laureates Charles Clements (peace, 1997), Dudley Herschbach (chemistry, 1986), and Richard Roberts (physiology or medicine, 1993) participated in the world premiere of The Brain Food Opera.

They took the stage to salute the King and Queen of Swedish Meatballs, asked the audience to stand for a "Moment of Science", and judged the "Great Intelligence Debate", in which participants squared off for $\mathbf{3 0}$ seconds, talking simultaneously.

The event ended with words of encouragement from master of ceremonies

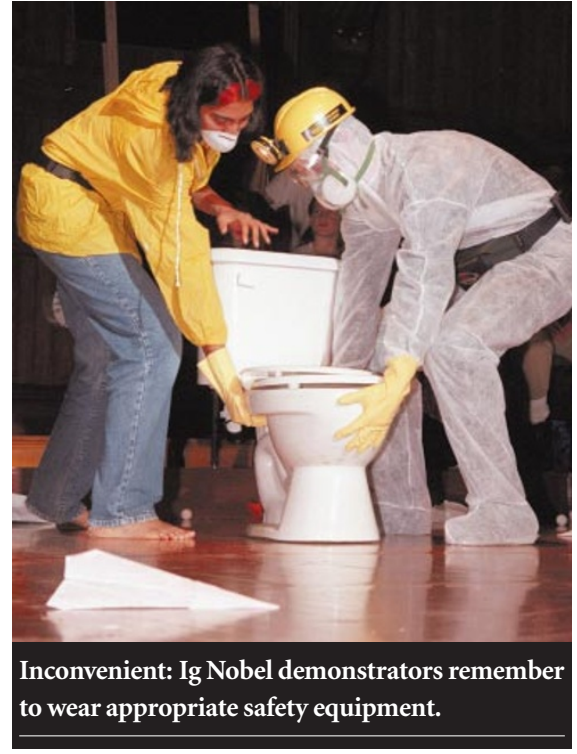

Marc Abrahams, editor of the Annals of Improbable Research: "If you didn't win an Ig Nobel prize tonight, and especially if you did, better luck next year."

http://www.improbable.com/ig/ig-top.html 